\title{
Oxide Nanowire Microfluidic Devices for Capturing Single-stranded DNAs
}

\author{
Marina MuSA, ${ }^{* 1 \dagger}$ Takao YASUI, ${ }^{1, * 2, * 3 \dagger}$ Zetao ZhU, ${ }^{* 1}$ Kazuki NAGaShIMA, ${ }^{22, * 4}$ Miki OnO, ${ }^{* 1}$ Quanli LiU, ${ }^{* 1}$ \\ Hiromi Takahashi, ${ }^{* 1}$ Taisuke Shimada, ${ }^{* 1}$ Akihide Arima, ${ }^{* 1}$ Takeshi Yanagida, ${ }^{* 4, * 5}$ and \\ Yoshinobu BABA $* 1, * 3, * 6 \dagger$
}

*1 Department of Biomolecular Engineering, Graduate School of Engineering, Nagoya University, Furo-cho, Chikusa, Nagoya 464-8603, Japan

*2 Japan Science and Technology Agency (JST), Precursory Research for Embryonic Science and Technology (PRESTO), 4-1-8 Honcho, Kawaguchi, Saitama 332-0012, Japan

*3 Institute of Nano-Life-Systems, Institutes of Innovation for Future Society, Nagoya University, Furo-cho, Chikusa, Nagoya 464-8603, Japan

*4 Department of Applied Chemistry, Graduate School of Engineering, The University of Tokyo, 7-3-1 Hongo, Bunkyo, Tokyo 113-8656, Japan

*5 Institute of Materials Chemistry and Engineering, Kyushu University, 6-1 Kasuga-Koen, Kasuga, Fukuoka 816-8580, Japan

*6 Institute of Quantum Life Science, National Institutes for Quantum and Radiological Science and Technology, 4-9-1 Anagawa, Inage, Chiba 263-8555, Japan

\begin{abstract}
Since DNA analysis is the fundamental process for most applications in biomedical fields, capturing DNAs with high efficiency is important. Here, we used several oxide nanowire microfluidic devices to capture CpG-rich single-stranded DNAs (ssDNAs) in different $\mathrm{pH}$ solutions. All the oxide nanowires exhibited the highest capture efficiency around $\mathrm{pH} 7$ with good capture efficiency shown by each metal oxide; $\mathrm{ZnO} / \mathrm{ZnO}$ core/shell $\mathrm{NWs}(71.6 \%), \mathrm{ZnO} / \mathrm{Al}_{2} \mathrm{O}_{3}$ core/shell NWs (86.3\%) and $\mathrm{ZnO} / \mathrm{SiO}_{2}$ core/shell NWs $(86.7 \%) . \quad \mathrm{ZnO} / \mathrm{Al}_{2} \mathrm{O}_{3}$ core/shell $\mathrm{NWs}$ showed the best performance for capturing ssDNAs under varying $\mathrm{pH}$, which suggests its suitability for application in diverse biological fluids. The capturing efficiencies were attributed to the interactions from phosphate backbones and nucleobases of ssDNAs to each nanowire surface. This finding provides a useful platform for highly efficient capture of the target ssDNAs, and these results can be extended for future studies of cancer-related genes in complex biological fluids.
\end{abstract}

Keywords Oxide nanowire, microfluidic device, single-stranded DNA, DNA capture, quantitative polymerase chain reaction $(\mathrm{qPCR})$

(Received November 27, 2020; Accepted January 15, 2021; Advance Publication Released Online by J-STAGE January 22, 2021)

\section{Introduction}

Since DNAs play important roles in living organisms as the carrier of genetic information ${ }^{1}$ and DNA analysis is the fundamental process for most applications in biomedical fields, capturing DNAs on various materials has been extensively studied for biomedical applications including nucleic acid extraction, ${ }^{2,3}$ biosensing ${ }^{4-8}$ and gene delivery. ${ }^{9-11}$ The adsorption of DNAs on solid surfaces has been investigated through various interactions, which include electrostatic interactions, ${ }^{12,13}$ hydrogen bonding and hydrophobic interactions, ${ }^{14,15}$ and $\pi-\pi$ coupling. ${ }^{4,16}$ Although most of the previous research highlighted the adsorption of DNA through electrostatic interactions between the positively charged surface and negatively charged

$\dagger$ To whom correspondence should be addressed.

E-mail:marinamusa2210@yahoo.com(M. M.); yasui@chembio. nagoya-u.ac.jp (T. Y.); babaymtt@ chembio.nagoya-u.ac.jp (Y. B.) phosphate backbone, ${ }^{6,12,13}$ in the case of single-stranded DNAs, we need to consider interactions with the nucleobases, which are readily exposed for interactions, and their charges that might influence the adsorption. ${ }^{5}$ Besides, the interactions between negatively charged oxide-based materials and negatively charged phosphate backbones have been reported based on the hard-soft acid-base (HSAB) principle. $^{4}$ Thus, finding compatible materials that can promote good interactions for capturing DNAs has received considerable interest.

The task of DNA analysis includes the formidable challenge of capturing a low copy number of DNAs from complex biological samples. Moreover, the availability of biological samples in diverse $\mathrm{pH}$; gastric juice $(\mathrm{pH} 1.32-3.57),{ }^{17}$ blood plasma ( $\mathrm{pH} 7.2),{ }^{18}$ liver bile ( $\left.\mathrm{pH} 7.8\right)$ and pancreatic juice (8.0 $8.3)^{19}$ has made the analysis more difficult. To overcome these challenges, a number of materials to capture DNAs have been reported, including gold nanoparticles, ${ }^{20-23}$ metal oxides, ${ }^{2,12,13,24}$ graphene oxide $(\mathrm{GO})^{4,16}$ and molybdenum disulfide $\left(\mathrm{MoS}_{2}\right)^{8,25}$ Among the materials, applications of metal oxides have 
a.

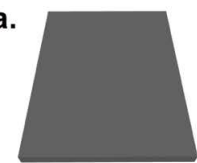

f.

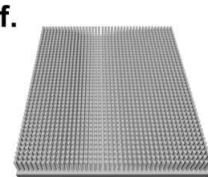

b.

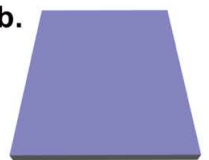

c.

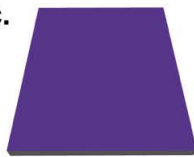

d.

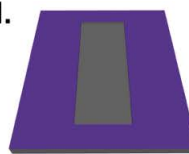

e.

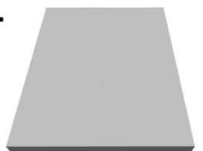

g.

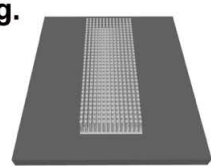

h.

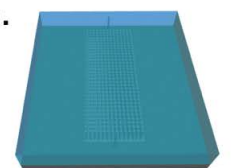

i.

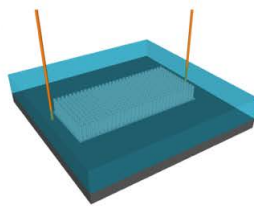

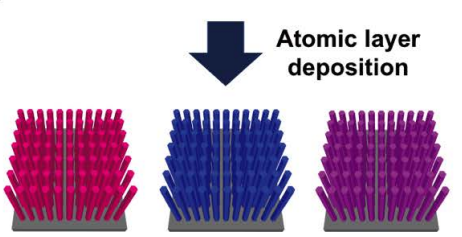

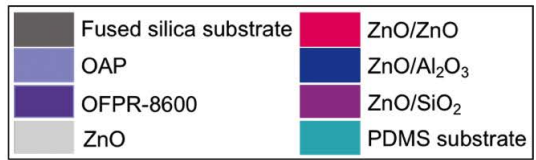

Fig. 1 Schematic illustrations for the fabrication of nanowires in microfluidic devices. (a) Precleaned fused silica substrate. (b) OAP spin coating. (c) OFPR-8600 spin coating. (d) Nanowire area pattern formed by photolithography, followed by pattern development using NMD-3. (e) Formation of $\mathrm{ZnO}$ seed layer by RF sputtering. (f) Hydrothermal growth of $\mathrm{ZnO}$ nanowires. (g) Removal of OFPR8600 photoresist followed by ALD of $\mathrm{ZnO}, \mathrm{Al}_{2} \mathrm{O}_{3}$, and $\mathrm{SiO}_{2}$. (h) Attachment of PDMS substrate by heating at $180^{\circ} \mathrm{C}$ for $2 \mathrm{~min}$. (i) Insertion of PEEK tubes into the inlet and outlet holes.

increased due to their good optical, electronic and catalytic properties, and biocompatibility. ${ }^{22,26}$ Metal oxide nanowires offer the advantages of a rigid framework ${ }^{28}$ and other diverse properties, which include large surface-to-volume ratio and ease of surface modification. ${ }^{29,30}$ Due to these advantages, applications of metal oxide nanowires to biomolecular analysis have been emerging. ${ }^{29-32}$

In this research, we studied the performance of hydrothermally grown zinc oxide nanowires ( $\mathrm{ZnO} \mathrm{NWs)}$ before and after surface modification with $\mathrm{ZnO}(\mathrm{ZnO} / \mathrm{ZnO}$ core/shell $\mathrm{NWs})$, aluminum oxide $\left(\mathrm{ZnO} / \mathrm{Al}_{2} \mathrm{O}_{3}\right.$ core/shell $\left.\mathrm{NWs}\right)$ and silicon dioxide $\left(\mathrm{ZnO} / \mathrm{SiO}_{2}\right.$ core/shell NWs) using the atomic layer deposition (ALD) method for capturing $\mathrm{CpG}$ rich singlestranded DNAs (ssDNAs). ssDNAs with $\mathrm{CpG}$ sites, which are naturally found in microbial DNA, are always associated with the biomarker of diseases due to epigenetic modifications, particularly abnormal methylation on the $\mathrm{CpG}$ sites that alter gene expression. ${ }^{33,34}$ Hence, their analysis has become important. The sequence of the ssDNAs used in this research was designed with consecutive cytosine and guanine $(\mathrm{C}+\mathrm{G})$ portion greater than $50 \%$ of the total DNA length as representative of CpG-rich DNA in cancer-related genes. ${ }^{35,36}$ Considering the different properties of the chosen metal oxides, which include their surface potential and class in HSAB, we investigated their performance to capture the target ssDNAs under varying $\mathrm{pH}$, to screen their potential for applications in diverse biological fluids.

\section{Methodology}

\section{Fabrication of $\mathrm{ZnO}$ nanowires}

Steps in the fabrication of the $\mathrm{ZnO}$ nanowires on a patterned area are shown schematically in Figs. 1a to 1f. A pre-cleaned fused silica substrate, $20 \times 20 \times 0.5 \mathrm{~mm}$ in size (Crystal Base Co., Ltd.) (Fig. 1a), was first spin-coated with 1,1,1,3,3,3-hexa methyldisilazane (OAP, Tokyo Ohka Kogyo Co., Ltd.) and then with OFPR-8600 (Tokyo Ohka Kogyo Co., Ltd.) (Fig. 1b and 1c, respectively). Next (Fig. 1d), a nanowire-fabricated area with length and width of 10 and $5 \mathrm{~mm}$, respectively, was formed by photolithography. The substrate was next immersed in NMD-3 solution (Tokyo Ohka Kogyo Co., Ltd.) to develop the area that was later used for growing nanowires. A seed layer of $\mathrm{ZnO}$ (thickness, $130 \mathrm{~nm}$ ) was sputtered on the substrate for 10 min using an RF-sputtering machine (SC-701Mk Advance, Sanyu Electron Co., Ltd.) (Fig. 1e). A hydrothermal method was applied to grow the nanowires by immersing the substrate into a mixture of $40 \mathrm{mM}$ hexamethylenetetramine (HMTA, Wako Pure Chemical Industries, Ltd.) and $40 \mathrm{mM}$ zinc nitrate hexahydrate (Thermo Fischer Scientific Inc.), followed by heating at $95^{\circ} \mathrm{C}$ for $3 \mathrm{~h}$ (Fig. 1f).

\section{$\mathrm{ALD}$ of $\mathrm{ZnO}, \mathrm{Al}_{2} \mathrm{O}_{3}$ and $\mathrm{SiO}_{2}$ layers}

After fabrication of the $\mathrm{ZnO}$ nanowires, the OFPR-8600 photoresist was removed (Fig. 1g) and an atomic layer deposition (ALD) system (Savannah G2, Ultratech Inc.) was used to deposit a thin layer of metal oxides with an approximate thickness around 5-6 nm. The ALD conditions differed depending on the type of metal oxides: i) $\mathrm{ZnO}$ (precursor, diethylzinc (DEZ) and water; temperature, $100^{\circ} \mathrm{C}, 55$ cycles); ii) $\mathrm{Al}_{2} \mathrm{O}_{3}$ (precursor, trimethylaluminum (TMA) and water; temperature, $150^{\circ} \mathrm{C}, 55$ cycles); and iii) $\mathrm{SiO}_{2}$ (precursor, tris(dimethylamino)silane (TDMAS) and ozone; temperature, $150^{\circ} \mathrm{C}, 55$ cycles).

\section{Fabrication of PDMS microchannel}

A 3-inch N-type $<100>$ silicon wafer (Advantech Co., ltd.) was spin-coated with $3 \mathrm{~mL}$ SU-8 3005 (Nippon Kayaku Co., Ltd.), followed by pre-baking at $95^{\circ} \mathrm{C}$ for $3 \mathrm{~min}$. The pattern for microchannel was formed by photolithography process with UV energy of $200 \mathrm{~mJ} / \mathrm{cm}^{2}$. The silicon wafer was then baked at 65 and $95^{\circ} \mathrm{C}$ for 1 and $2 \mathrm{~min}$, respectively. The microchannel pattern was developed using SU-8 developer (Nippon Kayaku Co., Ltd.), rinsed with isopropyl alcohol (IPA) (Kanto Chemical Co., Inc) and subjected to silanization treatment with trichloro( $1 H, 1 H, 2 H, 2 H$-perfluorooctyl)silane (Merck KgaA) for $2 \mathrm{~h}$. The mold was later used to make a microchannel on a polydimethylsiloxane (PDMS) substrate by mixing Silpot184 
(Dow Corning Toray Co., Ltd.) and curing agent Catalyst Silpot184 (Dow Corning Toray Co., Ltd.) at a ratio of 10:1. The resulting PDMS microchannel with size of $10 \mathrm{~mm}$ length, $5 \mathrm{~mm}$ width and $10 \mu \mathrm{m}$ height was then punctured using a $0.5 \mathrm{~mm}$ hole puncher (Harris Uni-Core) to make the inlet and outlet holes.

\section{Fabrication of oxide nanowire microfluidic devices}

The final fabrication step of the devices with the nanowires in the microchannel is shown schematically in Figs. 1h and $1 \mathrm{i}$. The surface of the PDMS substrate and the fused silica substrate with grown nanowires were treated using a plasma etching apparatus (Meiwafosis Co. Ltd.). The two substrates were bonded together by heating at $180^{\circ} \mathrm{C}$ for $2 \mathrm{~min}$ (Fig. 1h). Polyetheretherketone (PEEK) tubes, $0.26 \mathrm{~mm}$ inner diameter $\times$ $0.5 \mathrm{~mm}$ outer diameter (Institute of Microchemical Technology Co. Ltd.), were then inserted into the inlet hole and the outlet hole (Fig. 1i).

\section{FESEM and STEM-EDS characterizations of nanowires}

Surface morphologies of $\mathrm{ZnO} \mathrm{NWs}$ and $\mathrm{ZnO} / \mathrm{ZnO}$ core/shell NWs were observed using a field emission scanning electron microscope (FESEM) (SUPRA 40VP, Carl Zeiss AG). Elemental mappings of the $\mathrm{Al}_{2} \mathrm{O}_{3}$ - and $\mathrm{SiO}_{2}$-coated nanowires were obtained using a scanning transmission electron microscope equipped with an energy dispersive X-ray spectrometer (STEMEDS) (JSM-7610F, JEOL) operated at an acceleration voltage of $30 \mathrm{kV}$. The images were obtained with $512 \times 384$ pixels at scan rate of $0.1 \mathrm{~ms}$. The images were integrated for 100 cycles and the peaks of $\mathrm{Zn} K \alpha(8.630 \mathrm{keV}), \mathrm{O} K \alpha(0.525 \mathrm{keV}), \mathrm{Al} K \alpha$ $(1.486 \mathrm{keV})$ and $\mathrm{Si} K \alpha(1.739 \mathrm{keV})$ were used to construct the images.

\section{Zeta potential measurement}

The zeta potential of $50 \mathrm{ng} / \mathrm{L}$ DNA in Millipore water solution was measured at $25^{\circ} \mathrm{C}$ using a dynamic-light scattering spectrophotometer (ZETASIZER Nano-ZS Malvern Panalytical). For the metal oxide nanowires, $\mathrm{ZnO} / \mathrm{ZnO}$ core/shell $\mathrm{NWs}, \mathrm{ZnO} /$ $\mathrm{Al}_{2} \mathrm{O}_{3}$ core/shell $\mathrm{NWs}$ and $\mathrm{ZnO} / \mathrm{SiO}_{2}$ core/shell $\mathrm{NWs}$ were fabricated on a $2.6 \mathrm{~cm}$ wide $\times 3.7 \mathrm{~cm}$ long $\times 0.1 \mathrm{~cm}$ glass substrate followed by the zeta potential measurement (ELSZ2000 , Otsuka Electronics) in Millipore water at $25^{\circ} \mathrm{C}$.

Capture experiment for ssDNAs using nanowire microfluidic devices

The DNAs, primers and probes used in the capture experiment were obtained from Invitrogen, Themo Fisher Scientific, Inc. and their sequences are shown in Table 1. A DNA solution of $50 \mathrm{ng} / \mathrm{L}$ was prepared by dissolving the stock DNA in Millipore water. Hydrochloric acid ( $\mathrm{HCl}$, FUJIFILM Wako Pure Chemicals Corp., Ltd.) and sodium hydroxide ( $\mathrm{NaOH}$, Wako Pure Chemical Industries, Ltd.) solutions were used to vary the $\mathrm{pH}$ of the DNA sample solution to $\mathrm{pH} \mathrm{3,7}$ and 10 and the $\mathrm{pH}$ was measured using a $\mathrm{pH}$ meter (Horiba Scientific). The capture

Table 1 Sequence of the oligonucleotides used

\begin{tabular}{ll}
\hline Oligonucleotide & \multicolumn{1}{c}{ Sequence $\left(5^{\prime}-3^{\prime}\right)$} \\
\hline Probe & FAM-ATCGCGCTCTCGCGCTGACGG \\
Forward primer & ACGCGTACTGCGGTCG \\
Reverse primer & GCGTACGCGCGACG \\
61 Bases & ATACGCGTACTGCGGTCGCGATCGCGCTC- \\
& TCGCGCTGACGGTGCGTCGCGCGTACGC- \\
& GATT \\
\hline
\end{tabular}

a.

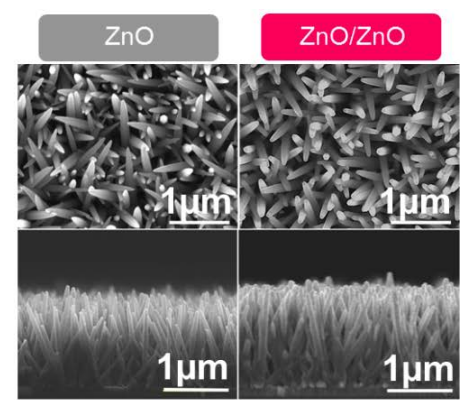

b.
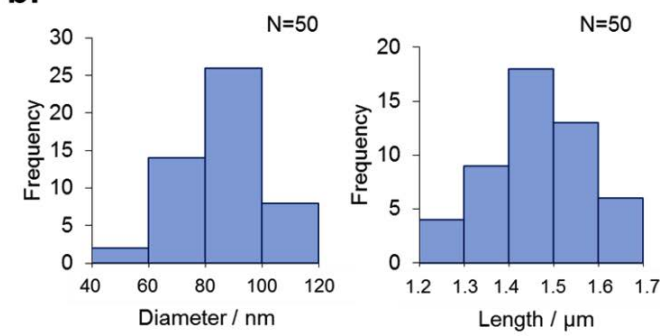

c.
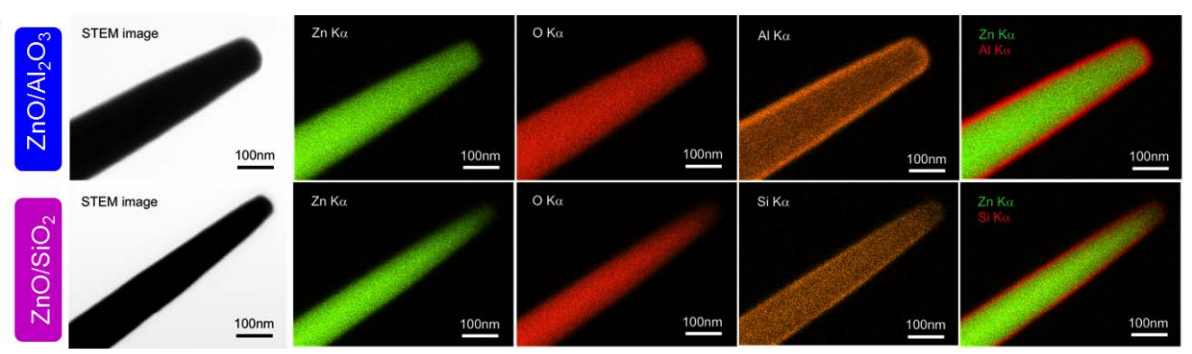

Fig. 2 Characterizations of metal oxide nanowires. (a) FESEM images of $\mathrm{ZnO}$ nanowires and $\mathrm{ZnO} /$ $\mathrm{ZnO}$ nanowires, top and cross-sectional views. (b) Size distribution of diameter and length of $\mathrm{ZnO} /$ $\mathrm{ZnO}$ core/shell nanowires. The number of measurements for diameter and length was 50. (b) STEMEDS elemental mapping of $\mathrm{ZnO} / \mathrm{Al}_{2} \mathrm{O}_{3}$ and $\mathrm{ZnO} / \mathrm{SiO}_{2}$ nanowires. For $\mathrm{ZnO} / \mathrm{Al}_{2} \mathrm{O}_{3}$ nanowires, $\mathrm{Zn}, \mathrm{O}$ and $\mathrm{Al}$ are respectively highlighted as green, red and orange for single elemental mappings, and $\mathrm{Zn}$ and $\mathrm{Al}$ are respectively highlighted as green and red for dual elemental mappings. For $\mathrm{ZnO} / \mathrm{SiO}_{2}$ nanowires, $\mathrm{Zn}, \mathrm{O}$ and $\mathrm{Si}$ are respectively highlighted as green, red and orange for single elemental mappings, and $\mathrm{Zn}$ and $\mathrm{Si}$ are respectively highlighted as green and red for dual elemental mappings. 

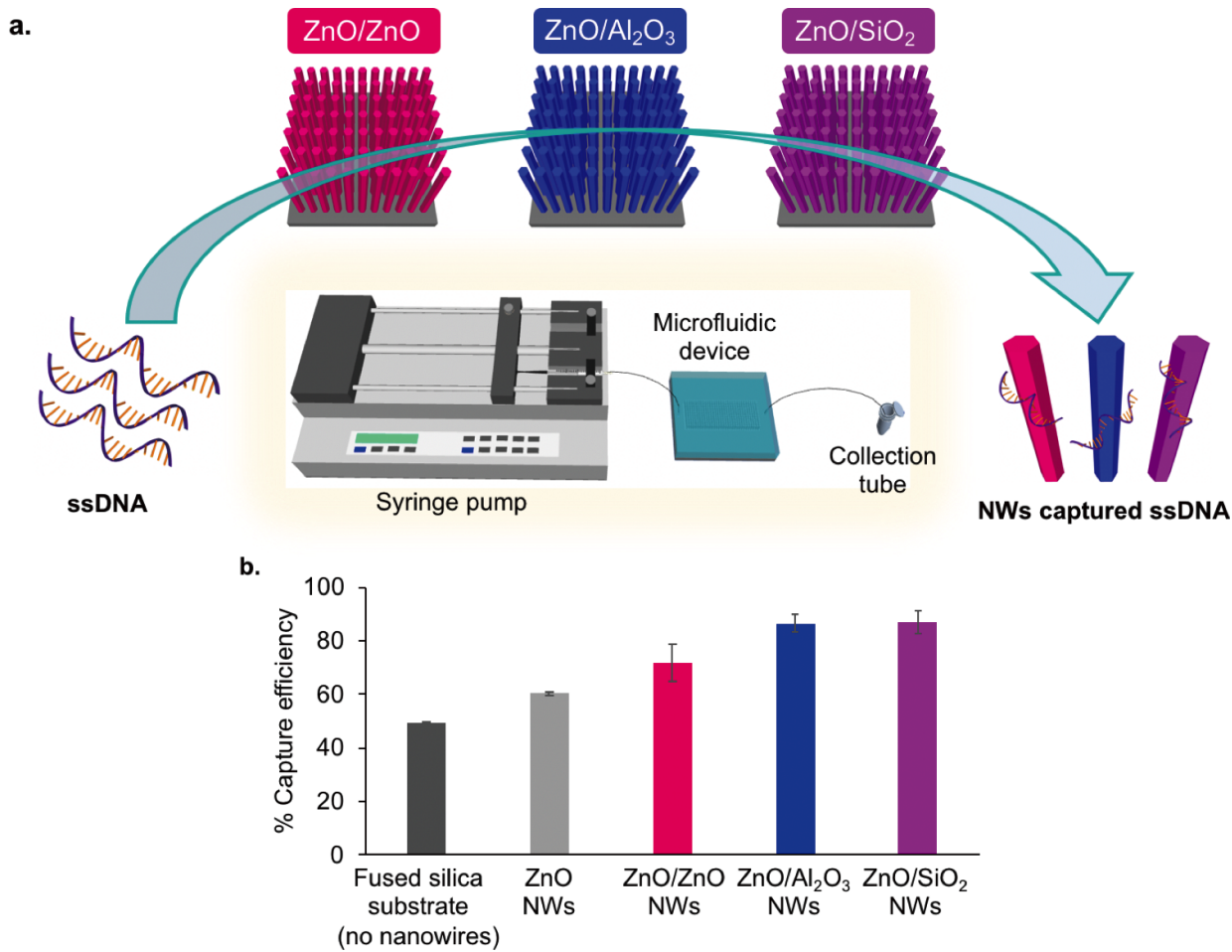

Fig. 3 Capture experiment for ssDNAs using different oxide nanowires in microfluidic devices. (a) Overview for capture in microfluidic devices. The device was connected to a syringe pump and a collection tube. (b) Capture efficiency of ssDNAs on different oxide nanowires: fused silica substrates (no nanowires); $\mathrm{ZnO}$ nanowires on the fused silica substrates, $\mathrm{ZnO} / \mathrm{ZnO}$ nanowires on the fused silica substrates; $\mathrm{ZnO} / \mathrm{Al}_{2} \mathrm{O}_{3}$ nanowires on the fused silica substrates; and $\mathrm{ZnO} / \mathrm{SiO}_{2}$ nanowires on the fused silica substrates. Error bars show the standard deviation for a series of measurements $(N=3)$. Experimental conditions: $50 \mu \mathrm{L}$ of $50 \mathrm{ng} / \mathrm{L}$ DNA solution; flow rate $5 \mu \mathrm{L} / \mathrm{min}$; sample pH 7 .

experiment was performed using a syringe pump system (KDS200, KD Scientific Inc.) at a flow rate of $5 \mu \mathrm{L} / \mathrm{min}$. Next, $50 \mu \mathrm{L}$ of Millipore water was introduced to remove any possible contaminations. Then, $50 \mu \mathrm{L}$ of $50 \mathrm{ng} / \mathrm{L}$ DNA solution was introduced into the inlet of the microfluidic device and the recovered amount was collected in a $1 \mathrm{~mL}$ centrifuge tube.

\section{Quantifications of DNA}

Analysis of the concentrations of recovered DNAs was performed using the PIKOREAL 96 quantitative polymerase chain reaction (qPCR) system (Thermo Fisher Scientific Inc.). A mixture containing $1 \mu \mathrm{L}$ DNA solution, $3.5 \mu \mathrm{L}$ Millipore water, $5 \mu \mathrm{L}$ TaqMan ${ }^{\circledR}$ Gene Expression Master Mix (Applied Biosystems, Thermo Fisher Scientific Inc.), and $0.5 \mu \mathrm{L}$ Custom TaqMan $^{\circledR}$ Gene Expression Assays (Applied Biosystems, Thermo Fisher Scientific Inc.) was pipetted into a 96-well reaction plate, sealed with an optical seal (Applied Biosystems, Thermo Fisher Scientific) and qPCR was conducted. The qPCR was carried out using the following cycling protocol: $2 \mathrm{~min}$ at $50^{\circ} \mathrm{C}, 10 \mathrm{~min}$ at $95^{\circ} \mathrm{C}, 50$ cycles of $15 \mathrm{~s}$ at $95^{\circ} \mathrm{C}$, and $1 \mathrm{~min}$ at $60^{\circ} \mathrm{C}$. The capture efficiency of ssDNAs was calculated using the equation below.

\section{$\%$ Capture efficiency $=$}

Amount of input DNA - Amount output DNA Amount of input DNA

\section{Results and Discussion}

ssDNA capture experiment using different oxide nanowire microfluidic devices

We used zinc oxide nanowires ( $\mathrm{ZnO} \mathrm{NWs)}$ as the core nanowires and coated them with selected metal oxides: zinc oxide $(\mathrm{ZnO} / \mathrm{ZnO}$ core/shell $\mathrm{NWs})$, aluminum oxide $\left(\mathrm{ZnO} / \mathrm{Al}_{2} \mathrm{O}_{3}\right.$ core/shell NWs) and silicon dioxide $\left(\mathrm{ZnO} / \mathrm{SiO}_{2}\right.$ core/shell NWs) for the capture of target ssDNAs. Our previous research reported on the optimal spacing between nanowires for capturing the target ssDNAs as they traversed through the nanowires. ${ }^{37}$ Hence, the ALD method for the fabrication of the core/shell nanowires was designed to give an approximate thickness of $5-6 \mathrm{~nm}$ to yield a similar size of nanowires for all metal oxides in order to achieve the optimal spacing between nanowires. The top and cross-sectional SEM views of the $\mathrm{ZnO} \mathrm{NWs}$ and $\mathrm{ZnO} /$ $\mathrm{ZnO}$ core/shell NWs showed slight increments in the nanowire size for $\mathrm{ZnO} / \mathrm{ZnO}$ core/shell NWs (Fig. 2a). The size distribution of $\mathrm{ZnO} / \mathrm{ZnO}$ core/shell NWs was representative of the core/shell nanowires that gave a maximum peak in the range of $80-100 \mathrm{~nm}$ and $1.4-1.5 \mu \mathrm{m}$, for the diameter and length, respectively (Fig. 2b). The STEM-EDS elemental mappings of $\mathrm{ZnO} / \mathrm{Al}_{2} \mathrm{O}_{3}$ and $\mathrm{ZnO} / \mathrm{SiO}_{2}$ nanowires indicated successful deposition of a thin layer of $\mathrm{Al}_{2} \mathrm{O}_{3}$ and $\mathrm{SiO}_{2}$ on the $\mathrm{ZnO}$ nanowires using the ALD method (Fig. 2c). ssDNAs were supplied into the oxide nanowire microfluidic devices using the syringe pump system and captured on the nanowires, while the uncaptured ssDNAs were collected and quantified using qPCR (Fig. 3a). The performance of different oxide materials for capturing ssDNAs 
a.

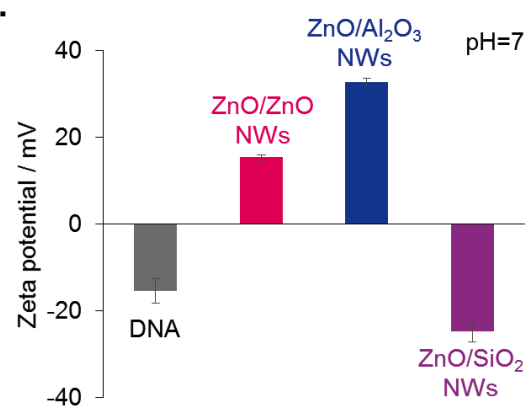

b.

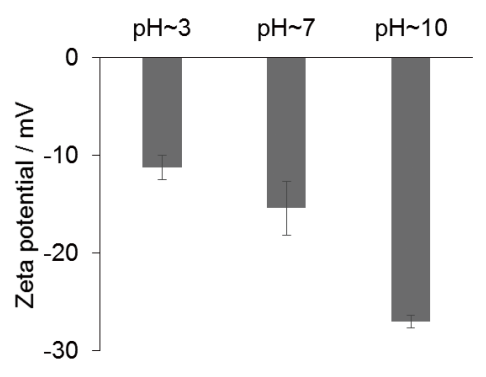

c.

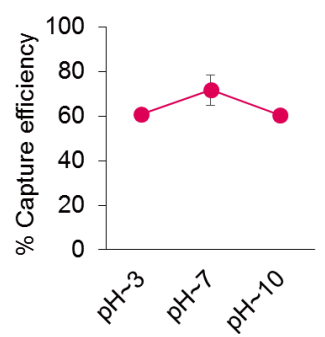

\section{$\mathrm{ZnO} / \mathrm{Al}_{2} \mathrm{O}_{3}$}

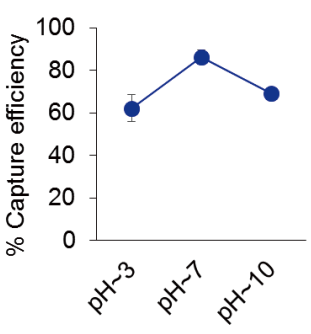

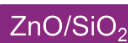

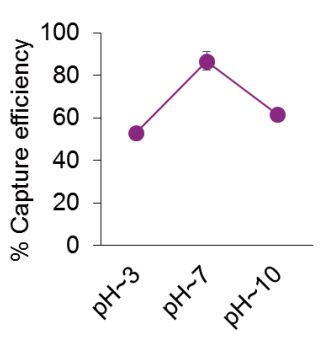

Fig. 4 The effect of $\mathrm{pH}$ values on capture efficiency of different oxide nanowires. (a) Zeta potential of ssDNAs and each nanowire type at $\mathrm{pH}=7$. (b) Zeta potential of ssDNAs at different $\mathrm{pH}$. (c) Influence of $\mathrm{pH}$ on the capture of ssDNAs on $\mathrm{ZnO} / \mathrm{ZnO}, \mathrm{ZnO} / \mathrm{Al}_{2} \mathrm{O}_{3}$ and $\mathrm{ZnO} / \mathrm{SiO}_{2}$ nanowires. Error bars show the standard deviation for a series of measurements $(N=3)$. Experimental conditions: $50 \mu \mathrm{L}$ of $50 \mathrm{ng} / \mathrm{L}$ DNA solution; flow rate $5 \mu \mathrm{L} / \mathrm{min}$; sample $\mathrm{pH} 3,7$ and 10 .

in neutral $\mathrm{pH}$ indicated an enhancement in capture efficiency by metal oxide nanowires compared to the fused silica substrate due to a larger surface-to-volume ratio possessed by the nanowires (Fig. 3b). Surface modification of ZnO NWs with thin layer $\mathrm{ZnO}$ by $\mathrm{ALD}$ yielded $\mathrm{ZnO} / \mathrm{ZnO}$ core/shell NWs that improved the capture efficiency from 60.5 to $71.6 \%$, possibly due to the increase in nanowire size resulting in the optimal spacing between nanowires sufficient for capturing the ssDNAs. As such, core/shell NWs were used in subsequent studies.

\section{Relationship between zeta potential and capture efficiency}

To understand the effect of surface charge on capture efficiency of ssDNAs, we measured the zeta potential of the metal oxide nanowires and ssDNAs at neutral pH (Fig. 4a). ssDNAs showed a negative zeta potential value, $-15.4 \mathrm{mV}$, due to the deprotonation of hydroxyl from phosphates, and for the metal oxide nanowires, $\mathrm{ZnO} / \mathrm{ZnO}$ core/shell $\mathrm{NWs}$ and $\mathrm{ZnO} / \mathrm{Al}_{2} \mathrm{O}_{3}$ core/shell NWs showed positive zeta potential values, $+15.4 \mathrm{mV}$ and $+32.9 \mathrm{mV}$, respectively whereas $\mathrm{ZnO} / \mathrm{SiO}_{2}$ core/shell NWs exhibited negative values of $-24.8 \mathrm{mV}$. Based on the assumption that the capture efficiency is related to only charged-based interactions between the surface of nanowires and phosphate backbone of ssDNAs, the highest capture efficiency should be exhibited by $\mathrm{ZnO} / \mathrm{Al}_{2} \mathrm{O}_{3}$ core/shell $\mathrm{NWs}(86.3 \%)$ or $\mathrm{ZnO} / \mathrm{ZnO}$ core/shell NWs $(71.6 \%)$ followed by $\mathrm{ZnO} / \mathrm{SiO}_{2}$ core/shell NWs $(86.7 \%)$. However, our studies showed that all of the metal oxide nanowires exhibited good capturing performance for ssDNAs near neutral $\mathrm{pH}$ (Fig. 3b), and $\mathrm{ZnO} / \mathrm{SiO}_{2}$ core/shell NWs exhibited the highest capture efficiency, which contradicts previous reports that highlighted the contribution to DNA capture as mainly being electrostatic interactions to negativelycharged phosphate backbone. ${ }^{6,13}$
Effect of pH on capture efficiency of different oxide nanowires

To investigate the capability of the metal oxide nanowires for capturing ssDNAs in diverse biological fluids, we performed the capture experiment under varying $\mathrm{pH} ; \mathrm{pH} \mathrm{3,7}$ and 10, which covered the range of $\mathrm{pH}$ for most biological fluids. The zeta potential of the ssDNAs under different $\mathrm{pH}$ conditions showed a decline in the values with increasing $\mathrm{pH}$ (Fig. 4b), and all of the metal oxides showed an increasing trend in capture efficiency from $\mathrm{pH} 3$ to 7 , followed by a decreasing trend to $\mathrm{pH} 10$ (Fig. 4c). We supposed that lower capture efficiency exhibited at $\mathrm{pH} 3$ and 10 compared to $\mathrm{pH} 7$ might be influenced by the charge of nucleobases as reported in previous research..$^{5,38}$ As the nucleobases are stable in their neutral form in the range of $\mathrm{pH} 5$ to 8, their charges are tunable at lower and higher $\mathrm{pH} .{ }^{39}$ At $\mathrm{pH} 3$, all of the metal oxides tend to be positively charged, which caused repulsion between the metal oxides and positively charged cytosine $\left(\mathrm{p} K_{\mathrm{a}}, 4.2\right)$ and adenine $\left(\mathrm{p} K_{\mathrm{a}}, 3.5\right) .^{39,40}$ At more extreme conditions, $\mathrm{pH} 10$, the surface charge of ssDNAs tuned to a highly negative charge as exhibited by the zeta potential value $(-27 \mathrm{mV})$ (Fig. 4b) due to the negatively charged phosphate backbone and the deprotonation of guanine $\left(\mathrm{p} K_{\mathrm{a}}\right.$, 9.2 -9.6) and thymine $\left(\mathrm{p} K_{\mathrm{a}}, 9.9\right)^{41}$ which inhibited the interactions with the negatively charged metal oxides. Apart from the charge on the phosphate backbone, the charge of individual nucleobases should be taken into consideration as it might have some influence on the capture efficiency.

The highest capture efficiency was reported at $\mathrm{pH} 7$ for all metal oxides, which suggested a more preferable interaction to ssDNAs bearing neutral charged nucleobases with core/shell NWs. More interestingly, $\mathrm{ZnO} / \mathrm{SiO}_{2}$ core/shell NWs, which possessed negatively charged surfaces showed higher capture efficiency than positively charged $\mathrm{ZnO} / \mathrm{ZnO}$ core/shell $\mathrm{NWs}$. 
Other than the effect of surface charges, we supposed that the relation between the capture efficiency and HSAB principle played an important role as reported in previous research based on the interactions between several metal oxides and phosphates according to this principle. ${ }^{4,42-44}$ In our case, both $\mathrm{ZnO} / \mathrm{Al}_{2} \mathrm{O}_{3}$ core/shell NWs and $\mathrm{ZnO} / \mathrm{SiO}_{2}$ core/shell NWs are classified as hard acids, which have preferable affinity towards the phosphates that are classified as hard bases; on the other hand, $\mathrm{ZnO} / \mathrm{ZnO}$ core/shell NWs are classified as a borderline acid, which will have a different affinity towards the phosphates. ${ }^{45-47}$ Higher capture efficiency exhibited by $\mathrm{ZnO} / \mathrm{SiO}_{2}$ core/shell $\mathrm{NWs}$ compared to $\mathrm{ZnO} / \mathrm{ZnO}$ core/shell $\mathrm{NWs}$ might be attributed to more preferable interactions between hard acid and hard base compared to those between borderline acid and hard base. $\mathrm{ZnO} /$ $\mathrm{Al}_{2} \mathrm{O}_{3}$ core/shell NWs, which are classified as hard acid, can also promote electrostatic attraction with ssDNAs, leading to high capturing performance of ssDNAs in a wide range $\mathrm{pH}$ compared to the other metal oxides.

\section{Conclusion}

We fabricated different types of core/shell nanowires, $\mathrm{ZnO} / \mathrm{ZnO}$ core/shell NWs, $\mathrm{ZnO} / \mathrm{Al}_{2} \mathrm{O}_{3}$ core/shell NWs and $\mathrm{ZnO} / \mathrm{SiO}_{2}$ core/ shell NWs in microfluidic devices, and we demonstrated their performance for capturing CpG-rich ssDNAs. The influence of $\mathrm{pH}$ on the capture efficiency of ssDNAs was investigated from low to high values of $\mathrm{pH}$ with the highest capture efficiency achieved at $\mathrm{pH} 7$ for all metal oxides. We concluded that for capturing ssDNAs, apart from the role of the phosphate backbone, the role of nucleobase should be taken into consideration due to the unbound nucleobase side that makes it readily exposed for interactions. Depending on the type of metal oxides, the capturing ability might vary due to the different properties of each metal oxide. Our findings showed the capability of the negatively charged surface of $\mathrm{ZnO} / \mathrm{SiO}_{2}$ core/ shell NWs to capture ssDNAs with high capture efficiency at neutral $\mathrm{pH}$, despite having similar surface charge, thus eliminating the effect of surface charge as the only factor for capturing ssDNAs. Thus, other than the effect of surface charge, we suggest that the HASB principle should be taken into consideration when capturing ssDNAs onto oxide nanowire surfaces. We proposed that for capturing ssDNAs, $\mathrm{ZnO} / \mathrm{Al}_{2} \mathrm{O}_{3}$ core/shell NWs showed good potential to be applied in diverse biological fluids due to high capture efficiencies exhibited under varying $\mathrm{pH}$ compared to $\mathrm{ZnO} / \mathrm{ZnO}$ core/shell $\mathrm{NWs}$ and $\mathrm{ZnO} /$ $\mathrm{SiO}_{2}$ core/shell NWs. This finding provides prospects for more expanded applications of the oxide nanowires in microfluidic devices to the analysis of $\mathrm{CpG}$ rich ssDNAs in cancer-related genes as well as the analysis of circulating microRNAs in diverse biological fluids. ${ }^{42}$

\section{Acknowledgements}

This research was supported by PRESTO (PMJPR19H9), Japan Science and Technology Agency (JST), the JSPS Grant-in-Aid for Young Scientists (A) 17H04803, the JSPS Grant-in-Aid for Exploratory Research 20K21124, the JSPS Grant-in-Aid for Scientific Research (S) 18H05243, the JSPS Grant-in-Aid for Scientific Research (B) 18H02009, the JSPS Grant-in-Aid for Scientific Research on Innovative Areas "Chemistry for Multimolecular Crowding Biosystems", and research grants from each of the following: the Murata Science Foundation, Advanced Technology Institute Research Grants 2019,
Foundation of Public Interest of Tatematsu, the Nitto Foundation, the G-7 Scholarship Foundation, and the Cooperative Research Program of the "Network Joint Research Center for Materials and Devices".

\section{References}

1. W. Zhou, R. Saran, and J. Liu, Chem. Rev., 2017, 117, 8272.

2. L. Chen, B. Liu, Z. Xu, and J. Liu, Langmuir, 2018, 34, 9314.

3. K. D. Clark, O. Nacham, H. Yu, T. Li, M. M. Yamsek, D. R. Ronning, and J. L. Anderson, Anal. Chem., 2015, 87, 1552.

4. B. Liu, L. Ma, Z. Huang, H. Hu, P. Wu, and J. Liu, Mater. Horizons, 2018, 5, 65.

5. X. Zhang, F. Wang, B. Liu, E. Y. Kelly, M. R. Servos, and J. Liu, Langmuir, 2014, 30, 839.

6. R. Pautler, E. Y. Kelly, P. J. J. Huang, J. Cao, B. Liu, and J. Liu, ACS Appl. Mater. Interfaces, 2013, 5, 6820.

7. S. A. Lim and M. U. Ahmed, Anal. Sci., 2016, 32, 687.

8. X. Wang, M. Yang, Q. Liu, S. Yang, X. Geng, Y. Yang, H. Fa, Y. Wang, and C. Hou, Anal. Sci., 2019, 35, 441.

9. K. A. Andrea, L. Wang, A. J. Carrier, M. Campbell, M. Buhariwalla, M. Mutch, S. L. MacQuarrie, C. Bennett, M. Mkandawire, K. Oakes, M. Lu, and X. Zhang, Langmuir, 2017, 33, 3926.

10. M. Rasoulianboroujeni, G. Kupgan, F. Moghadam, M. Tahriri, A. Boughdachi, P. Khoshkenar, J. J. Ambrose, N. Kiaie, D. Vashaee, J. D. Ramsey, and L. Tayebi, Mater. Sci. Eng. C, 2017, 75, 191.

11. E. Baghdan, S. R. Pinnapireddy, B. Strehlow, K. H. Engelhardt, J. Schäfer, and U. Bakowsky, Int. J. Pharm., 2018, 535, 473.

12. B. Liu and J. Liu, ACS Appl. Mater. Interfaces, 2015, 7 , 24833.

13. L. Ma, B. Liu, P. J. J. Huang, X. Zhang, and J. Liu, Langmuir, 2016, 32, 5672.

14. B. Shi, Y. K. Shin, A. A. Hassanali, and S. J. Singer, J. Phys. Chem. B, 2015, 119, 11030 .

15. J. Wu, H. Wang, A. Zhu, and F. Long, ACS Omega, 2018, 3, 5605.

16. Y. Ueno, K. Furukawa, A. Tin, and H. Hibino, Anal. Sci., 2015, 31, 875 .

17. Y. Liu, Y. Zhang, P. Dong, R. An, C. Xue, Y. Ge, L. Wei, and X. Liang, Sci. Rep., 2015, 5, 11936.

18. H. Vaisocherová, Z. Zhang, W. Yang, Z. Cao, G. Cheng, A. D. Taylor, M. Piliarik, J. Homola, and S. Jiang, Biosens. Bioelectron., 2009, 24, 1924.

19. P. Melamed and F. Melamed, JOP. J. Pancreas, 2014, 15, 552.

20. P. A. Mirau, J. E. Smith, J. L. Chávez, J. A. Hagen, N. Kelley-Loughnane, and R. Naik, Langmuir, 2018, 34, 2139.

21. H. Farrokhpour, S. Abedi, and H. Jouypazadeh, Colloids Surf. B, 2019, 173, 493.

22. L. B. Nie, X. L. Wang, S. Li, and H. Chen, Anal. Sci., 2009, $25,1327$.

23. X. Mao, A. Gurung, H. Xu, M. Baloda, Y. He, and G. Liu, Anal. Sci., 2014, 30, 637 .

24. T. Amano, T. Toyooka, and Y. Ibuki, Sci. Total Environ., 2010, 408, 480.

25. C. Zhu, Z. Zeng, H. Li, F. Li, C. Fan, and H. Zhang, J. Am. Chem. Soc., 2013, 135, 5998.

26. P. R. Solanki, A. Kaushik, V. V. Agrawal, and B. D. Malhotra, NPG Asia Mater., 2011, 3, 17. 
27. S. Andreescu, M. Ornatska, J. S. Erlichman, A. Estevez, and J. C. Leiter, "Fine Particles in Medicine and Pharmacy", 2012, Springer, Boston, MA.

28. S. Rahong, T. Yasui, T. Yanagida, K. Nagashima, M. Kanai, A. Klamchuen, G. Meng, Y. He, F. Zhuge, N. Kaji, T. Kawai, and Y. Baba, Sci. Rep., 2014, 4, 5252.

29. S. Rahong, T. Yasui, N. Kaji, and Y. Baba, Lab Chip, 2016, 16,1126

30. T. Shimada, T. Yasui, A. Yokoyama, T. Goda, M. Hara, T. Yanagida, N. Kaji, M. Kanai, K. Nagashima, Y. Miyahara, T. Kawai, and Y. Baba, Lab Chip, 2018, 18, 3225.

31. T. Yasui, T. Yanagida, S. Ito, Y. Konakade, D. Takeshita, T. Naganawa, K. Nagashima, T. Shimada, N. Kaji, Y. Nakamura, I. A. Thiodorus, Y. He, S. Rahong, M. Kanai, H. Yukawa, T. Ochiya, T. Kawai, and Y. Baba, Sci. Adv., 2017, 3, e1701133.

32. T. Yasui, T. Yanagida, T. Shimada, K. Otsuka, M. Takeuchi, K. Nagashima, S. Rahong, T. Naito, D. Takeshita, A. Yonese, R. Magofuku, Z. Zhu, N. Kaji, M. Kanai, T. Kawai, and Y. Baba, ACS Nano, 2019, 13, 2262.

33. J. Pohar, C. Yamamoto, R. Fukui, M.-M. Cajnko, K. Miyake, R. Jerala, and M. Benčina, J. Immunol., 2017, 198 , 2093.

34. M. Pavlovic, S. Chatterjee, A. Kats, and P. Neelakantaswamy, MOJ Auto Dis, 2017, 2, 10.

35. P. Khuu, M. Sandor, J. DeYoung, and P. S. Ho, Proc. Natl.
Acad. Sci., 2007, 104, 16528.

36. K. J. Fryxell and W. J. Moon, Mol. Biol. Evol., 2005, 22, 650.

37. M. Musa, T. Yasui, K. Nagashima, M. Horiuchi, Z. Zhu, Q. Liu, T. Shimada, A. Arima, T. Yanagida, and Y. Baba, Anal. Methods, 2021, 13, 337.

38. K. M. Koo, A. A. I. Sina, L. G. Carrascosa, M. J. A. Shiddiky, and M. Trau, Anal. Methods, 2015, 7, 7042.

39. B. Liu and J. Liu, Anal. Methods, 2017, 9, 2633.

40. P. Thaplyal and P. C. Bevilacqua, Methods Enzymol., 2014, $549,189$.

41. V. Verdolino, R. Cammi, B. H. Munk, and H. B. Schlegel, J. Phys. Chem. B, 2008, 112, 16860.

42. B. C. Trammell, M. A. Hillmyer, and P. W. Carr, Anal. Chem., 2001, 73, 3323.

43. H. Qiu, C. Liang, X. Zhang, M. Chen, Y. Zhao, T. Tao, Z. $\mathrm{Xu}$, and $\mathrm{G}$. Liu, ACS Appl. Mater. Interfaces, 2015, 7, 20835.

44. W. A. Schafer and P. W. Carr, J. Chromatogr. A, 1991, 587, 149.

45. R. G. Pearson, J. Chem. Educ., 1968, 45, 581.

46. T. Akitsu (ed.), "Basic Concepts Viewed from Frontier in Inorganic Coordination Chemistry", 2018, IntechOpen, United Kingdom.

47. S. Kaya, S. E. Kariper, A. Ungördü, and C. Kaya, J. New Results Sci., 2014, 3,1. 